Chapter 3

\title{
Heliogeophysical Aspects of Rheology: New Technologies and Horizons of Preventive Medicine
}

\author{
Trofimov Alexander and Sevostyanova Evgeniya \\ Additional information is available at the end of the chapter \\ http://dx.doi.org/10.5772/53661
}

\section{Introduction}

Geoecological and, first of all, cosmo-heliogeophysical factors exert a powerful regulatory influence on human vital activity [2]. Optimal level of blood circulation is of primary importance in the processes of human adaptation to changes of heliogeophysical environment. Cardio-vascular system is one of the first systems that are included in cascade of adaptive organism reactions. The normal functioning of this system provides rate of blood circulation and consequently tissue metabolism, which are optimal for certain conditions. There are studies that consider the effect of heliogeophysical factors: solar activity and disturbances of the geomagnetic field during the study on the state of the cardio-vascular system [8-13]. The possibility of influence of heliogeophysical factors in early human ontogenesis on the risk of development of cardiovascular diseases was revealed. Convincing data, demonstrating the dependence of the cardiovascular system functioning on changing heliogeophysical environment at different stages of ontogenesis were obtained [14,15]. However, despite the important results, most conducted to date research is devoted to cardiac function and central hemodynamics. At the same time it is known that the blood circulation in an organism is determined by the cardiac function, the state of the vascular bed and the rheological properties of blood. Rheological parameters have a significant impact on the volume and the linear blood flow, determining the values of total peripheral resistance and cardiac output of the blood circulation [16,17]. There are not many publications assessing rheological and hemostatic parameters of blood, which provide optimal rate of blood circulation at changes of heliogeophysical environment [1,18-20]. Thus, in the studies of laboratory of helioclimatopathology in 2008-2009 it was found that the dependence of many rheological (blood viscosity), hemostatic (platelet aggregation, clotting time, bleeding time, prothrombin index) and hemodynamic (arterial pressure, pulse wave velocity, endothelial function) pa- 
rameters varies with age. A significant age-related dynamics of associations of the physiological parameters with heliogeophysical factors in the prenatal ontogenesis of not only the persons surveyed but also of their parents was marked. It is shown the existence of genetically and epigenetically transferred from generation to generation "relay-race" of individual-generic sensitivity (steadiness) to the influence of various heliogeophysical factors, including galactic and solar flows of protons and electrons of different energies [4].

It is shown that disturbances of blood fluidity with blood hyperviscosity and hypercoagulation are one of the leading links in pathogenesis of chronic cardiovascular diseases (coronary heart disease, hypertension) and also their serious complications [21-23, 5-7]. Increase in blood viscosity and its aggregation potential increase hemodynamic disturbances at cardiovascular diseases and may promote myocardium and vascular remodeling, slowing of neoangiogenesis, endothelium dysfunctions. These processes can be both a consequence and a cause of hypertension [24].

Blood viscosity to a large degree is determined by the erythrocytes aggregation. Increased erythrocytes aggregation leads to occlusion of precapillaries and capillaries by erythrocytes aggregates, slow passage of erythrocytes in the narrow parts of blood channels, the general slowing of peripheral blood circulation. Erythrocytes aggregation is a direct cause of capillaries stasis. As a result of long-termed erythrocytes adhesion oxygen content in the erythrocytes decreases, carbon dioxide removes more difficult - all these processes negatively influence on an organism. Moreover the erythrocytes aggregation is accompanied by their damage with consequent isolation of erythrocytes clotting factors in the blood, which promotes hypercoagulation [22,25].

It is revealed that deformability of erythrocytes is decreased and erythrocytes and platelets aggregation is increased in hypertensive patients. A link between "rigidness" of erythrocytes and mass index of left ventricular myocardium was found. Changes of blood rheological parameters pass ahead disturbances of vasomotor endothelium function. Increase in blood viscosity complicates hemodynamic disturbances in hypertension and can promote myocardium and vascular remodeling [26].

Dependence of functional indices of the blood system on heliogeophysical disturbances is observed in patients with cardio-vascular pathology $[27,18,28,29,10]$. As an example, the studies, carried out on patients with coronary artery disease, show that at day of the beginning of geomagnetic disturbance, a sludge-phenomenon, perivascular changes, slowing of capillary circulation up to stasis are occurring [18].

It is shown that hypertensive crisis, attacks of angina pectoris, acute conditions of coronary artery disease and cerebrovascular disturbances may be a consequence of the changes of the hemodynamic, functional indices of the blood system, occurring at geomagnetic disturbance $[28,10]$.

All the above defines the importance of the study of complex dependencies of the blood rheological, hemostatic and biochemical indices on changes of heliogeophysical environment and the development of preventive measures in relation to patients with high heliomagnetosensitivity. 
The aim. To develop and test elements of a preventive system, reducing the risk of hemodynamic disturbances, crises and their complications in patients with arterial hypertension and high heliomagnetosensitivity of hemorheologic and cardiovascular parameters.

\section{Objectives}

1. To study the dependence of the rheological and hemodynamic parameters in patients with arterial hypertension on heliogeophysical factors at different stages of ontogenesis.

2. To study the influence of heliogeophysical factors on hemorheological parameters in patients with arterial hypertension in conditions of short-term geomagnetic deprivation of the blood samples.

3. To develop a basis of prevention of heliomagnetotropic reactions in patients with arterial hypertension with the use of light-water-mediated information holographic impacts (according to the patents RF № 2239860 from 05.05 .2003 and № 2342149 from 27.12.2008).

\section{The contingent and methods}

- Patients with arterial hypertension $(n=240)$, men and women aged 38 to 64 years.

- Blood samples ( $\mathrm{n}=240$ ) of these patients for the study of rheology (blood viscosity) and hemostatic (clotting time, prothrombin index, bleeding time) parameters.

- Methods of hemodynamic studies (blood pressure, heart rate, pulse wave velocity and endothelial function by the device "Tonocard").

- Hospital Anxiety and Depression Scale HADS.

- The computer program "Helios" to assess the functional dependence of the human systems on heliogeophysical situation in early ontogenesis (Certificate of state registration № 970125 from 24.05.1997). The program "Helios" contains database of 100 years in depth of the daily dynamics of the number and area of sunspots, solar radio emission in biotropic range of $220 \mathrm{mHz}$ and induction of the geomagnetic field. After introduction in a computer information of date of patients ' birth, the program algorithm allows to consider the distribution and value of the above mentioned factors in the different periods of prenatal organism development and to distinguish the system with the most heliomagnetosensitivity. In the present study the program has been used to estimate the dependence of hemorheological parameters on prenatal heliogeophysical situation.

- Data of satellite cosmophysical monitoring.

- Computer gaze-discharged visualization (GDV) (by K.G. Korotkov, 2002). 
- The installation, shielding the Earth's magnetic field (weakening of the full vector of geomagnetic induction more than 500 times) structured by Y. Zaitsev (Figure 1).

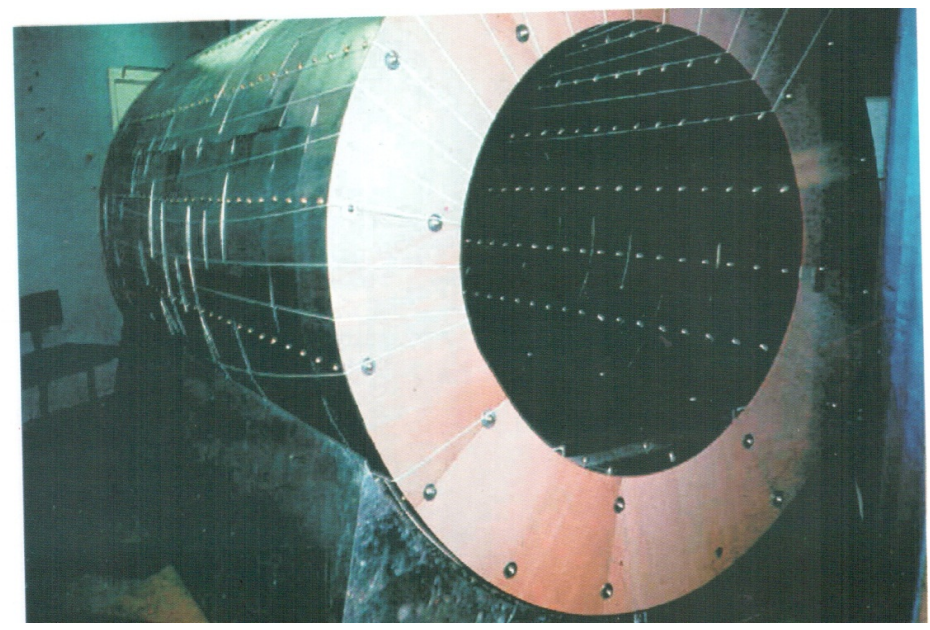

Figure 1. The installation, shielding the Earth's magnetic field structured by Y. Zaitsev

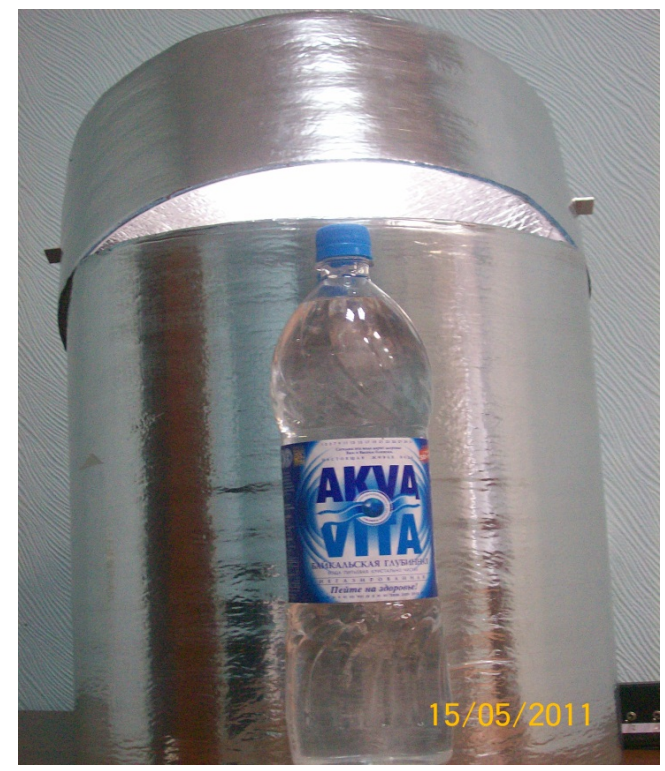

Figure 2. The screening device "TRODR-1" for light-holographic treatment of drinking water in the weakening geomagnetic field (A. Trofimov, G. Druzhinin, 2011) 
The portable screening device "TRODR-1" (by Trofimov A., Druzhinin G.) for light-holographic treatment of drinking water in the weakening of the total geomagnetic field vector in 300 times (Figure 2).

To determine the functional state of the cardio-vascular system the device "Tonocard" (Russia, Moscow) (Figure 3) was used. The device has Protocol № 14 П-09-24-044 of medical equipment, issued by 23.09.2009 by Federal Service on Surveillance in Healthcare and Social Development of Russian Federation.

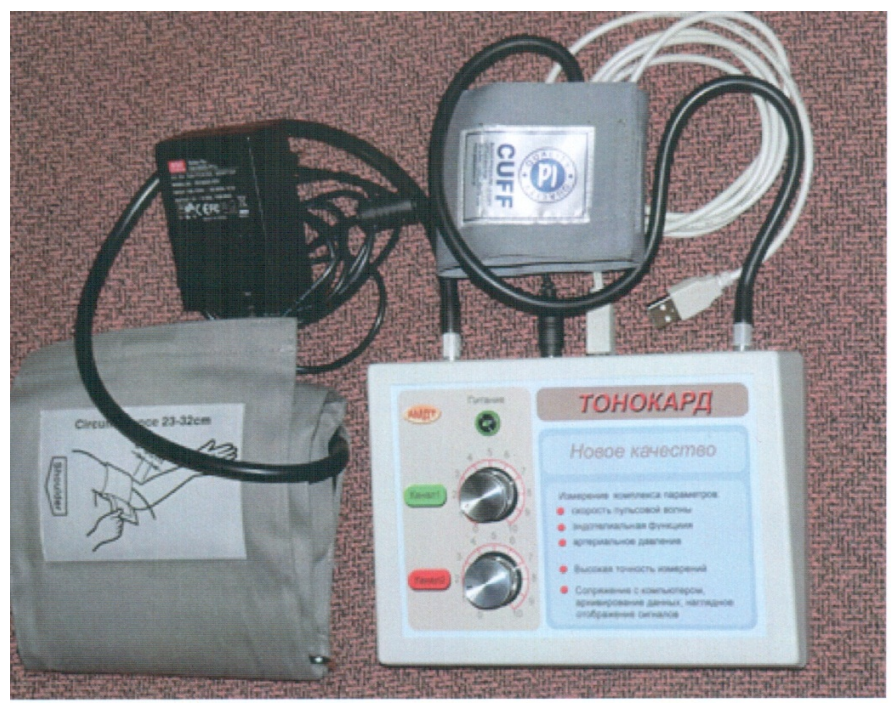

Figure 3. The device "Tonocard"

The following indices were evaluated: systolic and diastolic blood pressure, heart rate, velocity of pulse wave, endothelial function. Endothelial function was determined by the difference in pulse wave velocity before and after short-term (1 min.) occlusion of the brachial artery.

Fractional composition of blood lipoproteins was determined by the method of small-angled X-ray scattering (SAXS), which is analogous to X-ray diffraction analysis, by small-angle Xray diffractometer Siemens (Germany) in the blood samples of the tested volunteers, physicians with hypertension. The study was conducted at 5 time points before and after experimental course impacts: background (1), the control drinking water (2), holographically treated water (3), the distant impact of the illuminated control hologram (4) and the information capacious hologram (5). In test series (3 and 5) the hologram containing analog information about the complex helioprotective drugs was used.

Heliomagnetoprotective means on water and holographic basis. There is a method of creating a hologram, including separation of the laser beam into the reference and object branches so that the geometric length difference between the branches did not be more than length 
of the coherent laser source. The disadvantage of this method is that it is not allowed to enter into the hologram nonvizualized physiologically meaningful information. ISRICA together with "Holoart" created and patented (patent RF № 2239860 from 15.11.2004) a new type of hologram recording that uses water-mineral carrier of nonvizualised physiologically meaningful information about the quantum states of different drugs. The object of the holographic recording can be in a state of active or passive transfer of information, or used as the lens of the light beam. The present study used the holograms, which are the quantum analogues of the complex of antioxidant and anticoagulant agents.

Methods of mathematical (correlation) analysis of physiological and cosmophysical parameters.

\section{Results}

\subsection{Clotting blood system as an indicator of organism heliomagnetosensitivity in patients with hypertension}

A relationship between rheological, hemostatic, and other blood parameters and the intensity of heliogeophysical factors was detected. A relative increase of the whole blood viscosity $(8.50 \pm 0.27 \mathrm{cPs}$ vs. the normal value up to $5 \mathrm{cPs})$ was revealed in $99 \%$ of cardiovascular patients, this increase directly correlating with the number of sun spots on the day of the study $(\mathrm{r}=0.61 ; \mathrm{p}<0.05)$. In cardiovascular patients, high sensitivity of the blood system to heliogeophysical factors was detected: increase of solar activity was associated with a trend to a reduction of blood fluidity and increase to its coagulation (Table 1).

\begin{tabular}{lllllll}
\hline Parameter & \multicolumn{2}{l}{ Main group $(\mathbf{n}=\mathbf{3 7})$} & \multicolumn{3}{l}{ Reference group $(\mathbf{n}=\mathbf{3 1})$} \\
\cline { 2 - 6 } & $\mathrm{CT}$ & $\mathrm{PI}$ & $\mathrm{BT}$ & $\mathrm{CT}$ & $\mathrm{PI}$ & $\mathrm{BT}$ \\
\hline $\mathrm{SSN}$ & $-0,36^{*}$ & $0,46^{*}$ & $-0,01$ & $-0,06$ & $-0,15$ & $-0,04$ \\
\hline SR & $-0,07$ & $0,53^{*}$ & 0,14 & $-0,18$ & 0,03 & $-0,08$ \\
\hline Ap & $-0,41^{*}$ & $-0,41^{*}$ & $-0,31$ & $-0,14$ & 0,02 & 0,32 \\
\hline Protons & 0,06 & $-0,26$ & $-0,11$ & $-0,08$ & 0,01 & $0,38^{*}$ \\
\hline Electrons & $0,38^{*}$ & $-0,18$ & 0,15 & 0,13 & $-0,09$ & 0,33 \\
\hline
\end{tabular}

Note: CT - clotting time; PI - prothrombin index; BT - bleeding time;

SSN - sun spots number; SR - solar radiation in the $220 \mathrm{mHz}$ band; Ap - mean circadian geomagnetic index; protons solar particles with energy $>1 \mathrm{meV}$; electrons - solar particles with energy $>0,6 \mathrm{meV}$

Notes: * significant coefficients of correlation (Spearman, $p<0,05$ )

Table 1. Correlations between hemostasis parameters and heliogeophysical factors during study

No appreciable relationship of this kind was observed in the reference group ( $n=31)$. In our view, the obtained data indicate important for pathophysiology and clinic tendency to de- 
crease in blood fluidity at increase in solar activity and reflect the particular sensitivity of the blood to heliogeophysical factors at cardio-vascular diseases.

It is known that one of the basic elements, determining the blood viscosity and characterizing blood system as a whole is the functional state of erythrocytes. For its indirect assessment the erythrocytes sedimentation rate (ESR) was determined. A significant inverse correlation between ESR and area of sun spots $(\mathrm{r}=-0.33$; $\mathrm{p}<0.05)$ on the day of the study was detected in cardiovascular patients $(n=36)$; in other words, ESR decreased with increase of solar activity. No relationship of this kind was noted in the reference group $(n=19)$.

The spectral and frequency characteristics of the blood, recorded by computer GDV, are sensitive indicators of helio-biospheric effects. A direct correlation $(r=0.51 ; p<0.05)$ between the area of GDV fluorescence of blood samples from hypertensive and coronary patients $(n=65)$ and the intensity of solar activity, determined by the intensity of stream of protons with energy $>10 \mathrm{meV}$, and a significant inverse relationship $(\mathrm{p}<0.05)$ of these GDV parameters with the intensity of streams of solar electrons $(\mathrm{r}=-0.35)$, low-energy $(1-10 \mathrm{meV})$ protons $(\mathrm{r}=-0.54)$, and geomagnetic activity, evaluated by Ap index ( $\mathrm{r}=-0.38)$, were detected. No relationships of this kind were detected in the reference group $(n=20)$.

The presented data confirm the functional dependence of the hemorheological parameters on heliogeophysical environment at the moment of the study that is expressed differently in sick and healthy persons.

Operational internet information (web.site www.sec.noaa.gov) is an important new element of the prognosis of hemorheological dynamics in heliomagnetosensitive patients.

\subsection{Dynamics of the rheological parameters of blood (in vitro) and cosmophysical interfaces in short-term geomagnetic deprivation}

The role of the Earth's magnetic field to maintain hemostasis was determined in the modeled reducing the total vector of geomagnetic induction in 500 times - in conditions of hypogeomagnetic installation (HGMI). In an in vitro study, we found different variants of the reaction of the rheological parameters of blood to the weakening of the geomagnetic field: in the majority of cases $(61.5 \%)$ there was a decrease in blood viscosity, in $34.6 \%$ - increase in blood viscosity and no response $-3.9 \%$, i.e., decrease in blood viscosity with the weakening of the geomagnetic field is found in almost 2 times more than its increase. In conditions of the weakened geomagnetic field statistically significant decrease in the blood viscosity was revealed in patients with hypertension (in background conditions $-8.46 \pm 0.26 \mathrm{cPs}$, in HGMI $-8.05 \pm 0.21 \mathrm{cPs}, \mathrm{p}=0.01$ ).

In the control group there was a trend to a decrease in viscosity in HGMI, but there were no statistically significant differences.

Under experimental conditions of geomagnetic shielding, simulating individual elements of multilevel shielded megalopolis space, essentially modulating the degree of biotropic effects of natural physical factors, the group of cardiological patients exhibited reduction of correlations between blood viscosity and ESR (in vitro) and Wolf numbers (Figure 4). 

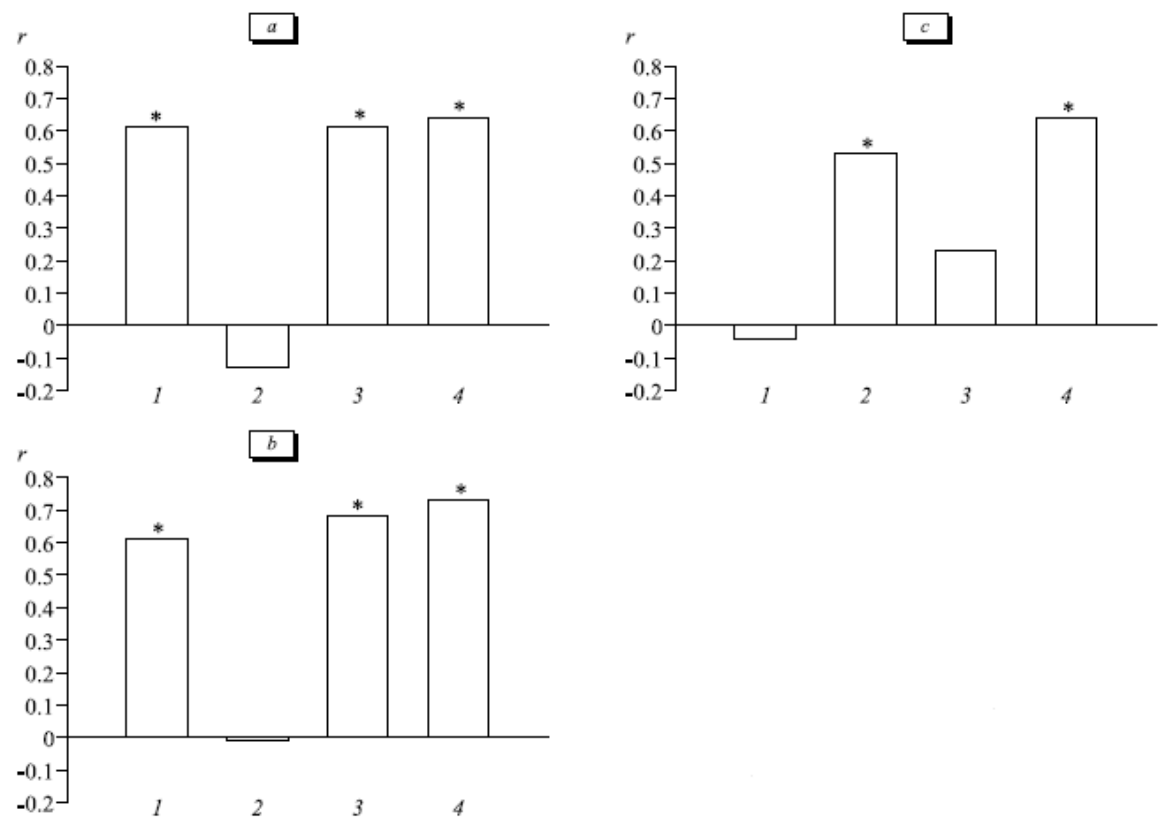

Figure 4. Dynamics of correlations between blood viscosity of cardiovascular patients and solar activity parameters in exposure of blood samples in vitro in attenuated GMF. a) number of sun spots; b) area of sun spots; c) protons (solar particles with $>1$ meV energy). *Significant coefficients of correlation (after Spearman; $p<0.05$.). 1) main group (basal values); 2) main group (hypogeomagnetic exposure); 3) reference group (basal values); 4) reference group (hypogeomagnetic exposure).

Short-term (30 $\mathrm{min}$ ) exposure of blood samples from cardiovascular patients to attenuated geomagnetic field led to a significant (9-fold) decrease in the number of significant relationships between blood GDV values and heliogeophysical factors. The only significant inverse correlation was detected: between the area of GDV fluorescence and intensity of protons with $>1 \mathrm{meV}$ energy $(\mathrm{r}=-0.38 ; \mathrm{p}<0.05 ; \mathrm{n}=65)$. No effects of this kind were detected in the reference group.

Thus, it was found that short-term 30-minute geomagnetic shielding leads to a significant decrease in blood viscosity and reduce its dependence on the intensity of solar and cosmic radiation. In the conditions of the hypogeomagnetic field weakening of associations of the blood system in patients with hypertension with the basic natural regulatory factors: solar activity and cosmic radiation appears. This can have mixed consequences for the functioning of the organism. In general, these data confirm the role of the geomagnetic field in maintaining of rheological homeostasis. Information concerning the level of geomagnetic induction in the analysis of coagulation, blood transfusions, surgery, determining the dose of anticoagulants, etc. should be evidence-based geo-ecological element of hemorheological monitoring of heliomagnetosensitive patients.

We evaluated possible relationship between rheological, hemostatic, and other parameters of the blood system and the heliogeophysical environment status not only during postnatal 
development, but also at the early stages of ontogenesis. The results indicated a significant association (inverse correlation) between cardiovascular patients' blood viscosity and geomagnetic induction values during the 1 st postnatal month $(\mathrm{r}=0.50 ; \mathrm{p}<0.05 ; \mathrm{n}=32)$. Significant $(p<0.01)$ inverse correlations between blood viscosity and Sun radiation intensity during the early ontogenesis were detected in 12 subjects of the reference group. Numerous significant coefficients of correlations $(\mathrm{p}<0.05)$, indicating an association of coagulation and fibrinolysis processes in the blood of hypertensive and coronary patients with prenatal heliogeophysical fluctuations (changes in solar radiation intensity and geomagnetic induction fluctuations) were detected throughout all periods of intrauterine development (Table 2).

\begin{tabular}{|c|c|c|c|c|c|c|}
\hline \multirow[t]{2}{*}{ Parameter } & \multicolumn{3}{|c|}{ Main group $(n=37)$} & \multicolumn{3}{|c|}{ Reference group $(n=31)$} \\
\hline & $\mathrm{CT}$ & $\mathrm{PI}$ & BT & $\mathrm{CT}$ & $\mathrm{Pl}$ & BT \\
\hline Ap DC & 0,13 & 0,44 & $-0,04$ & 0,26 & $-0,08$ & 0,005 \\
\hline Ap 2 & $-0,02$ & 0,10 & $0,46^{*}$ & 0,12 & 0,07 & 0,10 \\
\hline Ap 3 & 0,05 & 0,10 & 0,06 & $-0,13$ & $-0,38^{*}$ & $0,42^{*}$ \\
\hline Ap 7 & $-0,38^{*}$ & 0,26 & $0,35^{*}$ & $-0,23$ & $-0,21$ & 0,32 \\
\hline Ap 8 & $-0,01$ & $0,37^{*}$ & 0,25 & $-0,07$ & $-0,08$ & 0,15 \\
\hline Ap 10 & $-0,01$ & $-0,01$ & $0,50^{*}$ & 0,16 & 0,06 & 0,19 \\
\hline SSN 1 & $-0,15$ & $0,40 *$ & 0,27 & 0,20 & 0,14 & 0,16 \\
\hline SSN 2 & $-0,10$ & $0,38^{*}$ & 0,27 & 0,11 & 0,09 & 0,12 \\
\hline SSN 3 & $-0,09$ & 0,28 & $0,40^{*}$ & 0,13 & 0,02 & 0,09 \\
\hline SSN 4 & $-0,15$ & 0,28 & $0,37^{*}$ & 0,22 & 0,07 & 0,14 \\
\hline SSN 8 & $-0,23$ & 0,37 & $0,39^{*}$ & 0,05 & $-0,02$ & 0,10 \\
\hline SSN 9 & $-0,20$ & 0,28 & $0,41^{*}$ & 0,16 & 0,17 & 0,05 \\
\hline SR DC & $-0,52^{*}$ & $-0,08$ & 0,28 & $-0,003$ & $-0,02$ & 0,28 \\
\hline SR 1 & $-0,52^{*}$ & 0,26 & 0,35 & 0,16 & 0,18 & 0,20 \\
\hline SR 4 & $-0,45^{*}$ & 0,10 & $0,47^{\star}$ & 0,20 & 0,09 & 0,17 \\
\hline SR 5 & $-0,57^{\star}$ & 0,04 & $0,49^{*}$ & 0,09 & 0,13 & 0,17 \\
\hline SR 6 & $-0,58^{*}$ & $-0,01$ & $0,49^{*}$ & 0,25 & 0,18 & 0,08 \\
\hline SR 7 & $-0,63^{*}$ & $-0,01$ & $0,44^{*}$ & 0,14 & 0,22 & 0,04 \\
\hline
\end{tabular}

Notes:* significant coefficients of correlation (Spearman, $p<0,05)$

Ap - mean circadian geomagnetic index;

SSN-sun spots number;

$\mathrm{SR}$ - solar radiation in the $220 \mathrm{mHz}$ band;

Table 2. Type of correlations between hemostasis parameters and heliogeophysical factors during different stages (months) of embryogenesis 
Short-term attenuation of geomagnetic field led to repeated manifestation of inverse correlation between blood viscosity and intensity of geomagnetic induction during month 3 of early ontogenesis $(\mathrm{r}=-0.56 ; \mathrm{p}<0.05 ; \mathrm{n}=32)$ and a direct correlation between ESR and magnetospheric turbulence during the same prenatal period $(r=0.38 ; \mathrm{p}<0.05 ; \mathrm{n}=36)$. Month 3 of embryonal development, characterized by the appearance of the bone marrow hemopoietic function, can be considered as one of the "critical" periods for the formation of functional relationships in the blood system, determining its sensitivity to many exogenous factors, including the heliogeophysical ones.

Comparison of blood samples' GDV parameters before and after short-term exposure to attenuated geomagnetic field showed that these parameters of cardiovascular patients were also associated with prenatal heliogeophysical situation: they exhibited a significant direct correlation $(\mathrm{p}<0.05 ; \mathrm{n}=65)$ with the values of geomagnetic induction during months 1 and 2 of gestation ( $\mathrm{r}=0.58, \mathrm{r}=0.69$, respectively) and solar radiation in the $220 \mathrm{mHz}$ band during month 8 of intrauterine development $(\mathrm{r}=0.71)$ and during birth $(\mathrm{r}=0.66)$. No associations of this kind were observed under conditions of basal GMF ( 49 $000 \mathrm{nT}$ at the latitude of Novosibirsk) in any of the groups of patients.

The mechanisms of "heliogeophysical imprinting", discovered by Novosibirsk scientists 20 years ago [30], remain little studied. Involvement of the blood system in imprinting of prenatal environmental factors was detected in cardiovascular patients, which seems important for further studies of mechanisms, including the genetic ones [31], through which the memory about conditions of early development can be imprinted in the cells till adult status and be needed by adult body [32]. Imprinting of heliogeophysical environmental factors, presumably realized through DNA methylation and blocking of gene expression at the earliest stages of prenatal ontogeny [33], can be an important factor in the pathogenesis of cardiovascular and other diseases.

Hence, the dynamics of bioheliogeophysical conjunctions between some human blood parameters under conditions of simulated hypomagnetic space demonstrated its biotropic effect on the blood clotting system in cardiovascular patients: many blood values in these patients proved to be much more functionally dependent on the values of heliogeophysical factors than in patients without hypertension or coronary diseases during the study and during prenatal development.

The results of the work of the section identified the need of creation a system for forecasting the risk of hemodynamic disturbances for the prevention of complications of cardiovascular diseases in the context of geo-ecological factors at different stages of ontogenesis.

\subsection{Dynamics of sensitivity in vitro of hemorheological parameters in patients with hypertension to the effects of heliogeophysical factors and holographic information}

In 2 series of study it was assessed the dynamics of correlation dependence of the blood viscosity on different stages of ontogenesis in remote effects on the blood tube laser beam (control) and the laser beam, passing through "helioprotective enlightened hologram" with analogous information about antioxidants and anticoagulants. 
In the 1-series viscosity parameters in the control (no additional action) had no significant relationships with the intensity of the proton-electron flows at the time of the study. As the effect of the laser beam a significant direct dependence of viscosity on proton flows with energy about $10 \mathrm{meV}$ was revealed. In passing the laser beam through the protective hologram, this dependence was completely leveled (Table 3).

\begin{tabular}{cccccc}
\hline & Pr>1 $\mathbf{m e V}$ & Pr>10 meV & Pr>100 meV & El>0,6 meV & El>2 meV \\
\hline Background & 0,03 & $-0,11$ & $-0,29$ & 0,37 & 0,42 \\
\hline $\begin{array}{c}\text { (control) } \\
\text { test }\end{array}$ & $-0,32$ & $0,60^{*}$ & 0,21 & $-0,51$ & $-0,59^{*}$ \\
\hline $\begin{array}{c}\text { 2 (experiment) } \\
\text { test }\end{array}$ & $-0,27$ & 0,04 & $-0,43$ & $-0,58^{*}$ & $-0,52$ \\
\hline
\end{tabular}

Notes:* significant coefficients of correlation (Spearman, $p<0,05)$

Table 3. Correlations of blood viscosity (in tests with holograms in the 1-series of study) from electron-proton components of cosmic rays

In the 2nd series of studies the earlier findings were confirmed: at the impact of the laser a direct dependence on the proton flow with energies of $10 \mathrm{meV}$ occurs, helioprotective information containing in the hologram inverted a character of the relationship, inverse correlation appears (Table 4).

\begin{tabular}{|c|c|c|c|c|c|}
\hline & $\mathrm{Pr}>1 \mathrm{meV}$ & $\operatorname{Pr}>10 \mathrm{meV}$ & $\operatorname{Pr}>100 \mathrm{meV}$ & $\mathrm{El}>0,6 \mathrm{meV}$ & $\mathrm{El}>2 \mathrm{meV}$ \\
\hline $\begin{array}{c}\text { Background } \\
\text { viscosity }\end{array}$ & $-0,34$ & $-0,08$ & 0,11 & 0,24 & 0,36 \\
\hline $\begin{array}{l}1 \text { (control) } \\
\text { test }\end{array}$ & 0,03 & $0,75^{*}$ & 0,55 & $-0,10$ & $-0,23$ \\
\hline $\begin{array}{c}2 \text { (experiment) } \\
\text { test }\end{array}$ & 0,18 & $-0,27$ & $-0,22$ & 0,02 & 0,18 \\
\hline
\end{tabular}

Notes:* significant coefficients of correlation (Spearman, $p<0,05)$

Table 4. Correlations of blood viscosity (in tests with holograms in the 2-series of study) from electron-proton components of cosmic rays

Thus, the laser induces direct dependence of the blood system, its rheological parameters on solar proton flows, the helioprotective hologram eliminates this dependence.

Because the study used the blood of patients with hypertension, it should be borne in mind with intravenous laser therapy to prevent blood hypercoagulation and thrombotic complications during periods of increased solar corpuscular activity. 
Analysis of sensitivity of the blood system (by its viscosity) to the information contained in the holograms in a hypothetical appeal to the "memory" of an organism about helio-geophysical events in the prenatal ontogenesis was carried out.

From the data presented in Tables 5, 6, it follows that the laser effects on the blood (in vitro) is a stress factor that forces the blood system to access the prenatally shaped experience of interactions with heliogeophysical environment. Helioprotective information contained in the hologram dampens stress, showing another safeguard quality - stress-protective.=

\begin{tabular}{cccccccccccccccc}
\hline & $\begin{array}{c}\text { Geo } \\
\mathbf{- 1}\end{array}$ & $\begin{array}{c}\text { Geo } \\
\text { Con. }\end{array}$ & $\begin{array}{c}\mathbf{1} \\
\text { Geo }\end{array}$ & $\begin{array}{c}\mathbf{2} \\
\text { Geo }\end{array}$ & $\mathbf{3}$ & $\mathbf{4}$ & $\mathbf{5}$ & $\mathbf{6}$ & $\mathbf{7}$ & $\mathbf{8}$ & $\mathbf{9}$ & $\mathbf{1 0}$ & birth & $\begin{array}{c}\mathbf{+ 1} \\
\text { total }\end{array}$ \\
\hline background & $-0,02$ & 0,05 & 0,02 & 0,17 & $-0,29$ & $-0,02$ & 0,10 & $-0,19$ & $-0,14$ & $-0,14$ & 0,07 & $-0,33$ & 0,07 & $-0,10$ & $-0,02$ \\
\hline 1 test & 0,53 & $0,91^{* *}$ & $0,74^{*}$ & 0,17 & 0,29 & 0,64 & 0,69 & 0,50 & $0,79^{*}$ & $0,74^{*}$ & 0,69 & 0,43 & 0,43 & 0,55 & $0,74^{*}$ \\
\hline 2 test & 0,38 & $0,72^{*}$ & 0,53 & 0,33 & 0,10 & 0,48 & 0,57 & 0,14 & 0,50 & 0,43 & 0,60 & 0,12 & 0,29 & 0,45 & 0,57 \\
\hline
\end{tabular}

Notes: significant coefficients of correlation (Spearman)

* $-p<0,05 ; * *-p<0,01$

Geo -1, con.-induction of geomagnetic field (GMF) in the periods before and at the moment of conception

Geo 1-10-induction of GMF in the 1-10-th months of prenatal development

Geo Birth, +1- induction of GMF on the date of birth and in the 1-st month of postnatal life

Table 5. Correlations of blood viscosity ( 1 test - control; 2 test - with the use of hologram with illumination) from geomagnetic induction in prenatal period

\begin{tabular}{|c|c|c|c|c|c|c|c|c|c|c|c|c|c|c|c|}
\hline & $\begin{array}{c}\text { Geo } \\
-1\end{array}$ & $\begin{array}{l}\text { Geo } \\
\text { Con. }\end{array}$ & $\begin{array}{c}\text { Geo } \\
1\end{array}$ & $\begin{array}{c}\text { Geo } \\
2\end{array}$ & $\begin{array}{c}\text { Geo } \\
3\end{array}$ & $\begin{array}{c}\text { Geo } \\
4\end{array}$ & $\begin{array}{c}\text { Geo } \\
5\end{array}$ & $\begin{array}{c}\text { Geo } \\
6\end{array}$ & $\begin{array}{c}\text { Geo } \\
7\end{array}$ & $\begin{array}{c}\text { Geo } \\
8\end{array}$ & $\begin{array}{c}\text { Geo } \\
9\end{array}$ & $\begin{array}{c}\text { Geo } \\
10\end{array}$ & $\begin{array}{l}\text { Geo } \\
\text { birth }\end{array}$ & $\begin{array}{c}\text { Geo } \\
+1\end{array}$ & $\begin{array}{c}\text { Geo } \\
\text { total }\end{array}$ \\
\hline initial & 0,02 & 0,02 & 0,02 & $-0,21$ & 0 & $-0,19$ & 0,02 & $-0,10$ & $-0,14$ & $-0,14$ & $-0,10$ & $-0,14$ & 0,17 & 0,05 & $-0,07$ \\
\hline 1 test & 0,60 & $0,74^{*}$ & 0,60 & 0,69 & 0,55 & 0,38 & 0,60 & 0,64 & 0,43 & 0,24 & 0,41 & 0,24 & $-0,26$ & 0 & 0,57 \\
\hline 2 test & 0,48 & 0,52 & 0,48 & 0,33 & 0,36 & 0,14 & 0,48 & 0,41 & 0,21 & 0,17 & 0,26 & 0,12 & 0,05 & 0,17 & 0,36 \\
\hline
\end{tabular}

Notes: significant coefficients of correlation (Spearman)

* $-p<0,05 ; * *-p<0,01$

Geo -1, con.-induction of geomagnetic field (GMF) in the periods before and at the moment of conception

Geo 1-10-induction of GMF in the 1-10-th months of prenatal development

Geo Birth, +1 - induction of GMF on the date of birth and in the 1-st month of postnatal life

Table 6. Correlations of blood viscosity ( 1 test - control; 2 test - with the use of hologram with illumination) from indices of solar activity in prenatal period

Overall, the data on the meaning of ultra-weak environmental factors in hemorheological dynamics are presented. In addition, based on the data obtained it is promising during a la- 
ser therapy to take in account heliogeophysical situation and to use holographic helioprotective and anticoagulant filters.

\subsection{Dynamics of heliomagnetosensitivity of an organism in hypertension by the data of course clinico-physiological tests of water-holographic heliomagnetoprotective means}

It was noted that in the conditions of repeated short-term holographic impacts many hemodynamic parameters improved: systolic and diastolic blood pressure decreased, pulse wave velocity decreased, endothelial function improved.

At holographic impact, the inverse correlation dependence of endothelial function on such parameters as solar activity (the number and area of sunspots) and proton component of heliogeophysical environment was revealed, i.e. at high concentrations of protons endothelial function decreased (Table 7).

\begin{tabular}{llllll}
\hline & SSN & SSA & Ap & Am & Pr5 \\
\hline Background & 0,54 & 0,53 & - & - & 0,48 \\
\hline Control & - & - & - & - & - \\
\hline Hologram & $-0,45$ & $-0,48$ & - & - & $-0,47$ \\
\hline
\end{tabular}

Table 7. Significant $(p<0.05)$ correlations of endothelial function with heliogeophysical factors in the background, control and holographic testing

Attention is drawn to the same type of changes in correlations of hemodynamic indices with the proton component of the different energies in the process of transition measurement from the background to the control and from the background to the test.

Thus, according to data obtained Ph.D. V.Ya. Polyakov, course short-term use of holograms with analog helioprotective information (holographic glasses in 5 minutes, the source of "cold light" at a distance of $1.0 \mathrm{~m}$ ) leads to a change in the above parameters and their interfaces with heliogeophysical factors in the direction indicating helioprotective-effect [34].

The data are presented, demonstrating the expressed heliomagnetoprotective effect of protracted taking of drinking water treated with the use of light -holographic technologies, which is to improve the health and optimize the connection of endothelial function with heliogeophysical environment.

Holographic treatment of drinking water in hypopogeomagnetic installation by way patented in Russia (Russian patent 2342149 on 27.12.2008) led to the creation of a new protective product-heliomagnetoprotective drinking water. Its trial for 2 weeks on a group of volunteers under the control of the dynamics of lipid profile, which is of great importance to hemorheology, was to prove or disprove the expected heliomagnetoprotective effect in relation to the dependence of the content in the blood of lipoproteins of different density on biotropic heliogeophysical factors. 
It was carried out an assessment of the dynamics and dependencies of the distribution of the inhomogeneous electron density of lipoprotein macromolecules (nanoparticles of about $10 \div$ $103 \mathrm{~A}$ ), of their geometric and the weight invariants in venous and capillary blood of the subjects $(\mathrm{n}=4)$ on the intensity of X-ray and radio emission from the sun, the flow of electrons with energies greater than 0.6 and more than $2.0 \mathrm{meV}$, neutrons, protons with energies greater than 1.0, more than 10,0 and more than $100.0 \mathrm{meV}$, as well as the ion plasma temperature, as measured by satellites of Goes, at the holographic testing.

Two subjects ( $\mathrm{K}$ and $\mathrm{L}$ ) revealed different dynamics of investigated correlations. In the patient K., when taking holographic water, a direct correlation of high-density lipoprotein on the flow of solar protons increased; in the patient $\mathrm{P}$ at the direct holographic impact a direct dependence of low density lipoproteins on proton flow with energy of $100 \mathrm{meV}$ weakened (Table 8).

\begin{tabular}{llllll}
\hline The subject & Background & Control water & $\begin{array}{l}\text { Holographic } \\
\text { water }\end{array}$ & Control & Hologram+ \\
\hline $\mathrm{O}$ & 0,60 & 0,56 & 0,62 & 0,47 & 0,38 \\
\hline$\pi$ & 0,37 & 0,41 & 0,63 & 0,45 & 0,38 \\
\hline $\mathrm{K}$ & 0,50 & 0,50 & $0,77^{*}$ & 0,37 & 0,47 \\
\hline $\mathrm{P}$ & 0,58 & $0,67^{*}$ & $0,73^{*}$ & $0,77^{*}$ & 0,37 \\
\hline
\end{tabular}

Notes:* significant coefficients of correlation (Spearman, $p<0,05$ )

Table 8. Correlations (Spearman) of different density lipoproteins in the capillary blood with the daily values of the cosmic rays of different energies and charges

The data in the table provided by PhD T.V. Kuznetsova, concern only the parameters of capillary blood, in venous blood this dependence was not observed [34].

Therefore, this study allows to make the conclusion about the sensitivity of the blood system, its rheological characteristics to cosmo-heliogeophysical impacts and that the expressed association of hemorheological parameters with heliogeophysical environment is to a large degree determined by its exposure in the period of prenatal development. It was found that susceptibility to cardiovascular disease depended on the peculiarities of interaction of the adult with cosmo-heliogeophysical factors during its early ontogenesis. The data are presented indicating the possible formation of resistance to the development of cardiovascular pathology in individuals with a certain variant of dependence of the blood viscosity on the heliogeophysical conditions in the early stages of ontogenesis. It was found that the shortterm 30-minutes geomagnetic shielding led to a considerable decrease in blood viscosity and its dependence on the intensity of solar and cosmic radiation. These findings not only deepen the fundamental understanding of the solar-biosphere relations but also have practical significance for the development of therapeutic and preventive measures during periods of geomagnetic disturbances while managing patients with chronic cardiovascular pathology. 
To decrease organism heliomagnetosensitivity we applied helioprotective holograms, containing information on a number of drugs. The application of helioprotective holograms has led to the optimization of relationship of blood rheological parameters in patients with hypertension with heliogeophysical environment, reduce in dependence of blood viscosity indices on solar and cosmic radiation.

In the short-term repeated holographic exposures associations of endothelial function indices with heliogeophysical environment improved.

The course intake of holographically treated water led to helioprotective effect, which consists in a more favorable, antiatherogenic shift of lipid spectrum with increasing cosmic radiation.

\section{Conclusions}

Blood coagulation system reflects personal pronounced degree of dependence of hemorheological parameters and the whole organism in patients with arterial hypertension on solar and geomagnetic activity at different stages of ontogenesis.

Heliogeophysical environment is an important environmental risk factor for the development of hemorheological and hemodynamic disturbances in patients with arterial hypertension during periods of solar and geomagnetic perturbations.

Short-term exposure of blood samples in conditions of high-gradient changes of the magnetic field of the Earth in the installation, modulating its weakening more than 500 times, results in significant changes of associations of hemorheological and heliogeophysical parameters and proves the role of the geomagnetic field in the mechanisms of maintenance of the hemorheological constancy.

The short-term effect of holographic information on blood samples in patients with arterial hypertension, transmitted to them through a red helium-neon laser, reveals the early-ontogenetic memory of the organism, altering the expression and vector of dependence of the rheological parameters of blood on heliogeophysical situation in the prenatal period of development, as well as on the proton-electron component of solar (cosmic) rays at the moment of the investigation.

The short-term test light-mediated effect of holograms, containing helio-protective information, reveals its preventive character, since it establishes a significant inverse correlation dependence of endothelial function, pulse wave velocity and other hemodynamic parameters on the magnitude of the geomagnetic induction, which biotropic value was studied at experimental geomagnetic deprivation

The course ( 2 weeks) receiving by patients with arterial hypertension of drinking water with heliomagnetoprotective properties led to an improvement of well-being of patients, stabilization of hemodynamic parameters and manifestation of their advance (48 hours or more) 
correlation with heliogeophysical parameters allowing an organism to adapt to high-gradient fluctuations of the natural electromagnetic environment.

Heliomagnetoprotective means used in the form of drinking waterand light-holografic devices open new perspectives for their practical application in the system of geo-environmental prevention of hemorheological and hemodynamic disturbances in patients with arterial hypertension.

\section{Author details}

Trofimov Alexander* and Sevostyanova Evgeniya

*Address all correspondence to: isrica2@rambler.ru

International Scientific Research Institute of Cosmic Anthropoecology, Scientific Center of Clinical and Experimental Medicine of SB RAMS, Novosibirsk, Russia

\section{References}

[1] Chizhevskii AL. Biophysical mechanisms of erythrocyte sedimentation reaction. Novosibirsk; 1980.

[2] Kaznacheev VP., Trofimov AV. Essays on the nature of living matter and intelligence on the planet Earth. Problems of cosmoplanetary anthropoecology. Novosibirsk: Nauka, 2004.

[3] Kulikov VYu., Voronin AYu., Gaidul KV., Kolpakov VM. Biotropic characteristics of attenuated geomagnetic field. Novosibirsk; 2005.

[4] Trofimov AV., Sevostyanova EV. Dynamics of blood values in experimental geomagnetic deprivation (in vitro) reflects biotropic effects of natural physical factors during early human ontogeny. Bulletin of Experimental Biology and Medicine 2008; 146(1): 100-103.

[5] Becker RC. The role of blood viscosity in the development and progression of coronary artery disease. Cleve Clin. J.Med. 1993; 60(5): 353-358.

[6] Sweetnam PM., Thomas HF., Yarnell JWG, et al. Fibrinogen, viscosity and the 10year incidence of ischemic heart disease. The Caerphilly and Speedwell Studies. European Heart Journal 1996; 17: 1814-1820.

[7] Struijcer Boudier HAJ. Microcirculation in hypertension. Eur.Heart J. 1999; I(L): 32-37.

[8] Andronova TI., Deryapa NR., Solomatin AP. Heliometeotropic reactions of a healthy and a sick person. L.: Medicine, 1982. 
[9] Hasnulin VI. Hasnulina AV., Sevostyanova EV. Northern cardiometeopathies. Novosibirsk:Creative Union "South-West"; 2004.

[10] Breus TK., Komarov FI., Rapoport SI. The medical effects of geomagnetic storms. Clinical medicine 2005; 3: 4-12.

[11] Polyakov V., Trofimov A. Biorhytmological and clinico-functional features of arterial hypertension under geoecological conditions of the North. Alaska Med. 2007; 49(2): 120-126.

[12] Stoupel E., Assali A., Teplitzky I., Vaknin-Assa H., Abramson E., Israelevich P., Kornowski R. Physical influences on right ventricular infarction and cardiogenic shock in acute myocardial infarction. J.Basic Clin.Physiol.Pharmacol. 2009; 20(1): 81-87.

[13] Trofimov A. Impact of the heliophysical factors on man's lifespan in the circumpolar regions. Perspectives of intake of helio-geroprotectors. Int.J.Circumpolar Health 2010; 7: 356-360.

[14] Trofimov AV, Polyakov VYa., Devitsin DV., Sevostyanova EV. Phenomenon of heliogeophysical imprinting: new possibilities of predicting, diagnosis and prevention of cardiovascular diseases. In: Heliogeophysical factors and human health: proceedings of the International Scientific and Practical Symposium, 15-16 Nov., 2005, Novosibirsk. Novosibirsk; 2007

[15] Trofimov AV. About the possible influence of helio-geophysical factors in prenatal ontogenesis on duration of human life. New horizons of geroprevention: proceedings of the 6-th European congress of biogerontology, 30 Nov.-3 Dec.2008, Netherlands. Netherlands; 2008.

[16] Levtov VA., Regirer SA., Shadrina NH. Blood rheology. M.: Medicine, 1982.

[17] Ivanov KP. Successes and issues in study of microcirculation. Russian Journal of Physiology by name I.M. Sechenov 1995; 81(6): 1-17.

[18] Gurfincel YuI., Lyubimov VV., Oraevskii VN., Parfenova LM., Yurev AS. Effect of geomagnetic disturbances on capillary blood flow in patients with coronary heart disease. Biophysics 1995; 40(4): 793-799.

[19] Ionova VG., Sazanova EA., Sergeenko NP. Influence of helio-geomagnetic field on hemorheological characteristics of people. Aerospace and Environmental Medicine 2004; 38(2): 33-37.

[20] Sevostyanova EV., Trofomov AV., Kunitsyn VG., Bakhtina IA., Kozhevnikova IN. Heliogeophysical factors influence on the rheological properties of blood in patients with chronic cardio-vascular pathology. Bulletin of SB RAMS 2007; 5(127): 94-99.

[21] Dintenfass L. Hyperviscosity in Hypertension. Sydney; 1981.

[22] Dintenfass L. On changes in aggregation of red cells, blood viscosity and plasma viscosity during normal gestation. Clin. Hemorheol.1982; 2(3): 175-188. 
[23] Kitaeva ND., Shabanov VA., Levin GYa., Kostrov VA. Microrheology violation of erythrocytes in hypertensive patients. Cardiology 1991; 31(1): 51-53.

[24] Makolkin VI., Podzolkov VI., Pavlov VI., Samoilenko VV. Microcirculation state in hypertension. Cardiology 2003; 5: 60-67.

[25] Galenok VA., Gostinskaya EV., Dikker VE. Hemorheology in disorders of carbonate metabolism. Novosibirsk: Nauka, 1987.

[26] Shlyakhto VV, Moiseeva OM., Lyasnikova EA., Villevalde SV., Emelyanov IV. Rheological properties of blood and endothelial function in hypertensive patients. Cardiology 2004; 4: 20-23.

[27] Oranskii IE., Ilhamdzhanova DS Caught in the magnetic storms. Tashkent: Medicine, 1990.

[28] Komarov FI., Rapoport SI., Breus TK., Oraevskii VN., Elkis IS. To the problem of solar activity influence on clinically important types of pathology. Clinical Medicine 1995; 4(3):8-13.

[29] Stoupel E., Petrauskiene J., Kaledrene R., Abramson E., Sulkes J. Clinical cosmobiology. The Lithuanian study 1990 - 1992. Int. J. Biometeorol. 1995; 38(4): 204 - 208.

[30] Kaznacheev VP., Deryapa NR., Hasnulin VI., Trofimov AV. About the phenomenon of heliogeophysical imprinting and its importance in formation of the types of human adaptive reactions. Bulletin of SB AMS USSR 1985; 5: 3-7.

[31] Tycko B. Am J.Pathol. 1994; 3: 431-443.

[32] Holliday R. Philos.Transact. Royal Soc. 1997; 352(363): 1793-1797.

[33] Bird A. Welcome Trust Rev. 2000; 9: 47-49.

[34] Trofimov AV., Druzhinin GI. Information hologram: theoretical and practical perspectives for ecology and medicine of XXI century. Krasnoyarsk: Polikor, 2011. 